\title{
Resenha
}

MELLO, Marcelo Moura. Reminiscências dos quilombos: territórios da memória em uma comunidade negra rural. Editora Antropologia Hoje, São Paulo, 2012, 272pp.

\section{Criações de territórios quilombolas, uma analítica do alcance}

\author{
Vanessa Oginio \\ Universidade Federal de São Carlos, São Carlos, SP, Brasil \\ revant@usp.br
}

O livro Reminiscências dos quilombos. Territórios da memória em uma comunidade negra rural, escrito pelo Marcelo Moura Mello apresenta criaçôes de territórios quilombola. Os limites, as imagens e as demarcações destes territórios são delineados através do conteúdo das narrativas; lembranças dos nativos e das relaçóes de poder envolvidas. Através da pesquisa de campo em Cambará, no Rio Grande do Sul, o trabalho se estende para além de uma descrição antropológica, como também para contribuições teóricas e metodológicas a respeito de pesquisas feitas sobre comunidades quilombolas, assim como contribuiçóes para a abordagem analítica dos dados obtidos durante a pesquisa de campo. Com uma escrita envolvente e precisa, Mello leva-nos a ver uma comunidade negra rural a partir das distâncias e tempos que cada olhar pode alcançar.

O livro é estruturado em seis capítulos. Nos três primeiros capítulos há em comum a discussão acerca das dinâmicas desencadeadas pela assunção quilombola trazendo um debate com a abordagem feita por meio da história e de estudos sociais. Já o capítulo quatro circunscreve-se detidamente sobre a fonte documental como registro de formação histórica de Cambará. Os capítulos cinco e seis trazem uma primorosa recriação do tempo, espaço e imagens do lugar por meio dos documentos escritos e relatos orais.

Segundo Mello, o termo "comunidades remanescentes de quilombos" é uma categoria em disputa, em um jogo de significado polissêmico. Com o marco legal 
institucional de reconhecimento jurídico, esse termo é legitimado pelo artigo 68 da Constituição Federal de 1988, no entanto, argumenta-se que durante os períodos da década de setenta e de oitenta houvera distintas apropriaçôes do termo "quilombo" como símbolo de resistência negra. De modo que somente a partir da década de setenta que os estudos das populaçóes negras em meio rural passaram a receber maior atenção (: 39). E somente por volta da década de noventa é que houve um considerável incremento de investigaçóes sobre as comunidades negras rurais. Entretanto, segundo Mello, as reinvindicaçóes de reconhecimento como comunidades remanescentes de quilombo levaram a uma inflexão fundamental, a ênfase da base conceitual passou da condição camponesa para a condição étnica.

Argumenta-se que a teoria da etnicidade fora a matriz teórica que fundamentou a negação de uma série de atributos normalmente atrelados aos grupos a que o artigo 68 baseou-se. Desse modo surgiu a proposta de ressemantizar o conceito de remanescentes de quilombos, e nesta ressemantização da categoria os antropólogos atuaram como mediadores entres diferentes campos prático-discursivos, articulando as percepções e reinvindicaçôes dos sujeitos a perspectivas teóricas em um contexto no qual os órgãos estatais demandavam critérios que subsidiam sua atuação (: 49). O que estaria em jogo neste aspecto, conforme sugere Mello apoiando-se nas argumentaçôes de Arruti (2008), é a passagem entre o duplo registro classificatório: o nativo e o normativo. Os antropólogos estariam na posição de mediação entre as experiências locais e a categoria jurídica.

Sendo assim, com a ênfase na etnicidade e na autoatribuição, logrou-se o rompimento com a imposição de significados cristalizados, rechaçando o uso de critérios fundados no naturalismo (raça), historicismo e culturalismo. No entanto, a partir desta constatação, Mello põe em questão se essa ressemantização não implica também ressemantização das categorias nativas.

Mello destaca que o investimento teórico e conceitual feito para refletir sobre o dispositivo constitucional amparou-se em perspectivas que já estavam consolidadas nas ciências sociais muitos antes da emergência dos remanescentes. E argumenta, posicionando a sua metodologia analítica, que o mais produtivo é seguir as advertências de Almeida (2002) e Arruti (2008), atentando-se para a diversidade de percepçóes sobre a categoria remanescentes de quilombos; investigando quais são as correspondências traçadas pelos sujeitos a partir de suas experiências vividas. 
Diferente das abordagens analíticas que se baseiam no argumento histórico nas críticas do reconhecimento de remanescentes de quilombos, Mello posiciona-se a favor do conceito “campo negro" de Gomes (2006). Segundo Mello, a rentabilidade do conceito "campo negro" não se circunscreve somente às comunidade de fugitivos; por meio desta noção é possível pensar a dimensão relacional entre distintas espacialidades dos mundos da escravidão e da pós-emancipação, no sentido de que muitas famílias e indivíduos adotaram diferentes estratégias para se territorializar, de tal modo que não formam territórios isolados, mas sim conectam espaços e pessoas (: 57$)$.

No capítulo dois, "Mobilização da 'memória' e da trajetória histórica”, Mello produz um deslocamento além da dimensão política, rumo à dimensão moral das reinvindicações indentitárias. Neste caso, ao invés de instrumentalização, trata-se de justificação. Observam-se duas dimensóes de efeitos na teoria da etnicidade, a instrumentalização para benefícios e direitos; e a noçôes de justiça formadas a partir da experiência moral. Além dessas dimensóes de efeitos, Mello vai além ao trabalhar com a memória. Memória, aqui, é arquitetada como formação de um sentimento de pertencimento a um grupo (: 64), que não é somente a lembrança dos fatos passados, mas também estabelece relaçóes de ordem moral. É numa articulação entre lembranças e experiências que Mello nos leva aos atos de rememoração. De tal modo que as relações entre a oralidade e a escrita, assim como a experiências vividas, vão ao encontro da criação de tempos, espaços e memórias.

Mello teve em sua pesquisa de campo contato com arquivos, principalmente documentos de arquivos que tiveram início no contexto de produção de laudo, que é, de certa forma, uma técnica pela qual fundamenta o reconhecimento de direitos. Entretanto, como afirma o autor, as fontes documentais e narrativas não se circunscrevem a questões de ordem metodológica, isto porque, como já assinalado, Mello atenta-se para as conexões com as experiências vividas dos sujeitos. Não se trata de uma reificação dos relatos orais por meio dos documentos escritos, mas sim de elucidação de supressões, ausências, lacunas e silenciamentos que são fatores constitutivos do arquivo (: 79). Os documentos, portanto, aparecem numa abordagem analítica como algo que remete ao passado e que está povoado por vozes de homens e mulheres de Cambará, que tem efeitos de conhecimento na reconstrução do passado. 
O capítulo três, "Cambará e suas situaçôes”, trata do campo interétnico, no qual raça e racismo referem-se a uma série de situaçóes vividas no presente e no passado (: 85). Segundo Mello, as categorias "moreno" e "negro" são racializadas no sentido que se acredita que a essência racial é manifestada pela cor da pele e por características físicas. No entanto, a identificação do grupo é repleta de fraturas (: 85). Sendo assim, Mello utiliza o termo "famílias negras" para se referir a um conjunto de pessoas que se concebem distintas dos vizinhos - considerando que Cambará nunca fora um território isolado. Mesmo reconhecendo as relaçóes existentes tanto com outras comunidades negras e indígenas, Mello, concentra-se, no entanto, nas relaçóes dos moradores de Cambará com os brancos. O fundamento para tal ênfase se justifica pelo fato de que os brancos, além de empregadores dos negros, são eles que manifestam mais preocupação quanto às divisóes que podem surgir nessa história de quilombo (: 89).

Mello destaca as relaçóes de reciprocidade assimétrica, em que efeitos de racismo; interesse; atos de egoísmo; necessidade dos brancos de sempre estar por cima, revelam o caráter restrito das relaçóes de reciprocidade entre negros e brancos. Um dos exemplos que confirma esta relação assimétrica é a disparidade econômica. Além dessa assimetria, Mello argumenta que essas relaçóes com os brancos são constantemente realimentadas. Entretanto, houvera mudanças nos detalhes do cotidiano. Mello observa as disputas desencadeadas e as sutis mudanças na correlação de forças locais, de modo que a inclusão e a exclusão, e os limites da comunidade ganharam novos contornos. E que a resolução de questôes práticas acontecem de forma pessoalizada, relaçóes face a face (: 113). Segundo o autor, é a dinâmica entre os efeitos desencadeados pelos órgáos de reconhecimento e os códigos locais de justiça que deve ser investigada: a ação das famílias de Cambará não é uma mera reação dos fluxos desencadeados pelo Estado, tampouco sua organização política é uma mera reprodução em microescala dos padrôes característicos dessas entidades .

Nos três últimos capítulos, Mello faz um deslocamento analítico, adentrando-se nas particularidades circunscritas ao território de Cambará e nas categorias de identificaçóes presentes que são acionadas. O leitor acompanha a (re)criação desse contexto na medida em que tempos, espaços e memórias se entrecruzam.

O capítulo quatro, "Quilombos e suas reminiscências", aborda a formação territorial de Cambará no período compreendido entre o segundo quartel e o fim do século XIX, argumentando-se que este fora o contexto anterior dos chamados eventos marcantes na 
história de Cambará, assim como a existência de territórios negros durante o período escravista, fora também um aspecto negligenciado pela historiografia que se ocupou da estrutura fundiária sulina.

Segundo Mello, os laços familiares durante o período escravista foram decisivos para a permanência de ex-escravos na regiáo e para a acolhida de outras famílias negras no local. A documentação encontrada sobre este período se baseava na memória genealógica da comunidade, o que fundamenta a compreensão da história territorial de Cambará, tanto no presente como no passado, através da referência do parentesco, pois, no caso das famílias negras, o parentesco e o apadrinhamento resultaram na acolhida de diversas famílias.

Mello, diante de sua análise conclui que o tempo genealógico é instaurado da duração e dos direitos do grupo; e que a memória é genealógica pelo fato dela inscrever relaçôes familiares na história do grupo, transmitindo a continuidade temporal do lugar e das pessoas que vivem ali (: 153).

No capítulo cinco, "Território inscrito", o foco se volta para as narrativas e seus efeitos de conhecimento, há um descolamento de perspectiva. Mello atenta-se para não cristalizar os relatos sobre o território e não trata-los somente em sua dimensão simbólica. O confronto com a transmissão oral, segundo Mello, revela não só a correspondência entre dito e escrito, como também distintas mediaçôes estabelecidas entre os fatos e os detalhes ausentes nos documentos escritos.

As narrativas descritas trazem, segundo Mello, noções de justo e injusto, servindo de base para os princípios de justificação utilizados nas situaçóes práticas com as quais o grupo se defronta. Em outras palavras, as noçóes de justo e injusto tornam-se explícitas quando são acionados elementos da memória para legitimar as disputas territoriais. As questóes sobre racismo são constitutivas como parte do pano de fundo na operação de rememoração dos sujeitos de pesquisa.

Entre as relaçóes entre o passado e o presente estão os rastros, tanto materiais como em fotos ou objetos -, como também a paisagem do território que acionam o processo de rememoração. Sendo assim, a partir das imagens da memória, Mello traz uma reconstituição da formação e da história de Cambará. Uma reconstituição trazida por um deslocamento de foco e de escala, uma mudança de olhar. Mello aproxima-se do micro, no sentido de tornar explícitos detalhamentos que levam para as associaçóes entre pessoas e lugares. 
O território de Cambará, a partir desse foco e escala, é figurado num processo de transposição de lembranças, de modo que os afetos, as emoçóes, e os sentimentos estáo intimamente relacionados ao território (: 194).

Para além da história e dos registros em forma de arquivos como um instrumento de lembranças do passado, Mello mostra a importância das questóes morais estabelecidas nas relaçóes entres os sujeitos, parentes e não parentes de Cambará, um senso de justiça que se produz, entre o passado e o presente.

Em "O regime de criação", último capítulo, Mello traz avanços analíticos para o debate sobre relaçóes entre tempo, espaço e memória. Pode-se dizer, de certa forma, que se trata de uma analítica do alcance. Mello mostra como o regime de criação coloca em xeque temporalidades rígidas e destaca as continuidades e descontinuidades entre servidão e liberdade, uma vez que, em Cambará, as histórias envolvendo o passado escravista e o trabalho são extremamente relevantes na vida diária das pessoas (: 208). No entanto, Mello ressalta que pouco se fala da vida dos escravos, mas, fala-se muito de viver como escravo.

Através da elucidação das narrativas dos sujeitos de pesquisa, Mello faz uma inversão de discurso sobre o tema da escravidão. Quem fala como foi e/ou como é viver como escravo são as próprias pessoas que vivenciaram; parentes; e/ou aqueles que viveram nos contextos específicos do grupo de moradores de Cambará.

Logo no início do capítulo, Mello atenta-se para a questão situacional da relação entre pesquisador e nativo. No caso, trata-se de uma preocupação a respeito da(s) temporalidade(s) envolvida(s) na experiência do grupo de moradores de Cambará. Mello é meticuloso a este respeito principalmente por defrontar nos seus dados de pesquisa relatos e memórias que levam ao alcance de outras temporalidades; há casos em que se observa uma linha muito tênue entre liberdade e escravidão.

Segundo Mello, toda uma geração de Cambará foi “cria” em fazendas e estâncias de famílias brancas, onde recebiam alimentação, vestimenta e moradia em troca de serviço (: 217). A necessidade da busca de serviço, segundo Mello, gerava a mobilidade das pessoas, por um lado, mas, por outro, os vínculos de parentesco permitiam o acesso e os direitos da terra.

Se no capítulo cinco é mostrado um território inscrito pelas memórias, neste vemos, além da memória, a escravidão inscrita nos corpos desses moradores. Mello utiliza o termo 
geografia do corpo (: 232) ao se referir às marcas e cicatrizes que dão forma e expressam a trajetória de vidas dos grupos de moradores de Cambará.

Nesta etnografia, fica explícito que política e moralidade circundam as questôes vividas pelos moradores de Cambará. A disputa sobre direitos da terra; as noçốes de justo e injusto; o termo viver como escravo; as relaçóes de parentesco tornam-se categóricos no sentido de que informam sobre o mundo vivido pelos sujeitos de pesquisa e permeiam as relaçóes de poder existentes no território.

A terra, aqui, vai além do problema de demarcação de território, trata-se também de trazer para perto do leitor reminiscências de vidas marcadas pela escravidáo. Marcas que envolvem toda uma paisagem que se constitui em Cambará, desde uma luz, uma estrada, ou uma árvore, como também uma foto e os próprios corpos das pessoas. Mello traz-nos em uma envolvente trama de memórias afetivas e processos de rememoração dos sujeitos que nos levam para conexóes entre passado e presente. 